\title{
Identifying clusters of cycling commuters and travel patterns: The case of Quelimane, Mozambique
}

\author{
Classio Joao Mendiate ${ }^{a}$, Julio Alberto Soria-lara ${ }^{b}$, and Andres Monzon ${ }^{c}$ \\ ${ }^{\mathrm{a}}$ Transport Research Center- TRANSyT, Avda. Profesor Aranguren, Universidad Politecnica de Madrid, Madrid, Spain; ${ }^{\mathrm{b}}$ Universidad Politecnica \\ de Madrid, Madrid, Spain; 'Ingeniería Civil: Transportes, Avda. Profesor Aranguren s/n, Universidad Politecnica de Madrid, Madrid, Spain
}

\begin{abstract}
Limited attention has been paid to the analysis of cycling in the context of Sub-Saharan Africa (SSA). However, understanding cycling and cycling patterns in SSA is crucial for implementing a more effective cycling-oriented policy. Using the city of Quelimane, Mozambique, as a case study, this paper aims to understand cycling mobility in SSA cities by identifying clusters of cycling commuters and mapping their trip patterns. A survey was conducted to explore the socio-demographic aspects of the population and commuter attitudes toward cycling. The underlying factors structuring the population sample were determined by means of factor analysis, and a clustering process was applied. Cyclists' travel patterns were then recreated to assess the influence of road quality on cycling. The results identified three clusters of cycling commuters: informal workers with children, short-distance students, and occasional cyclists. The clusters were based on household composition, employment status and cycling frequency to work/school. It was found that over $40 \%$ of cycling trips took place within the city periphery and about $10 \%$ between the city periphery and suburban areas. Most people cycle to carry products to sell in local markets and as a bicycle-taxi. The study findings provided a clear understanding of commuter cyclists, and can serve as an empirical basis for developing more targeted policies to encourage cycling.
\end{abstract}

\section{KEYWORDS}

Bicycle; cluster; commuting; cycling-use variables; Quelimane city; sociodemographic variables

\section{Introduction}

Cycling is currently being promoted as a sustainable mode of transport (Van Cauwenberg et al., 2018; Winters et al., 2010) because it does not emit any pollutants (Massink et al., 2011) and occupies little space. It is also flexible, affordable and efficient in crowded urban areas (Heesch et al., 2015). Notwithstanding these benefits, cycling levels in many cities around the world are still considerably low (Heesch et al., 2014). In some cities in developed countries, low rates of cycling may be associated with high vehicleownership rates (Yao \& Wang, 2018), high living standards (Dimitriou, 2006), and land-use and housing policies that generate long distances and give rise to a culture of motorized-trips (Yang \& Zacharias, 2016).

Adaptation rates for cycling in developing countries can be explained by its association with rurality and poverty, and the perception of the bicycle as an inferior mode of transport (Diaz Olvera et al., 2008; Pendakur, 2005). However, there are still some exceptions where cycling is the predominant commuting mode, either due to the poor quality of public transport or to the fact that cycling is cheap and offers flexible job opportunities (Nkurunziza et al., 2012). This is the case of some African cities such as Tamale, Ghana, and Ouagadougou, Burkina-Faso, among others (Abane, 2011; Acheampong \& Siiba, 2018). The modal share of cycling in some of these cities is estimated to be as much as 30\%
(Wallrapp \& Faust, 2008), although this figure is currently in decline due to a wide range of local anti-cycling measures such as banning cycling from the most prestigious places in the city (Alando, 2017) and to the consideration of cycling as an outdated mode of transport (Pochet \& Cusset, 1999).

Numerous pro-cycling initiatives have been enacted in many cities across the world, including the installation of cycling infrastructures and facilities (Pucher et al., 2010), public awareness campaigns to promote safe on-road behavior (Assailly, 2017) and residential and job allocation to reduce travel distances (Oakil et al., 2016). However, these initiatives have a limited impact in Sub-Saharan African (SSA) cities due to a lack of empirical mobility data, which makes it difficult to have a real diagnosis of potential cycling users. Cycling policies and initiatives developed in western cities cannot usefully be exported to SSA, reinforcing the need to develop ad hoc studies in this region. These studies should set out to cover several aspects, such as the generation of mobility databases and local knowledge on cycling patterns, and a better understanding of the role of cycling in achieving sustainable mobility. They should be validated by specific pilot studies designed to test policy measures for improving cycling levels.

This research aims to identify clusters of cycling commuters and map their travel patterns in the context of African cities. The analysis also considers some built-environment aspects such as the urban fabric and the quality of 


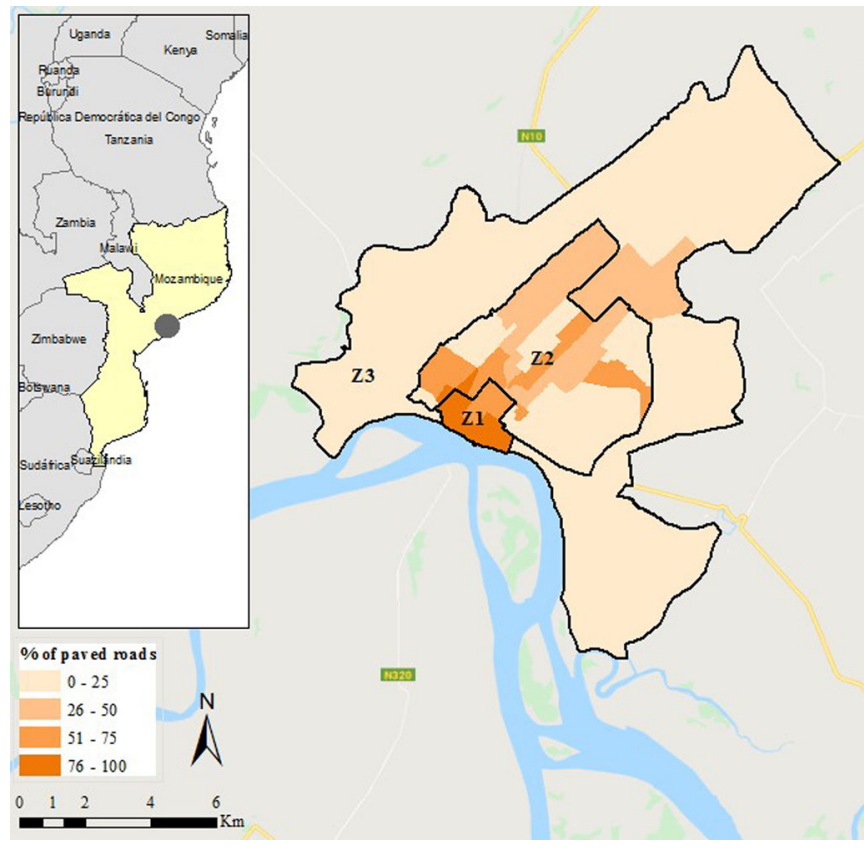

Figure 1. Case study of Quelimane: zones and road quality.

the road infrastructure, in addition to the lack of reliable public transport services. The clusters consider socio-demographic and cycling-use variables. The case study refers to the city of Quelimane, Mozambique. The remainder of the paper is organized as follows: Section 2 discusses previous studies in the field; Section 3 describes the case study and methods for analysis, while Section 4 presents the main results. Finally, Section 5 highlights some concluding remarks and further research lines.

\section{Theoretical background: the identification of cycling clusters}

There are an increasing number of studies that seek to cluster commuter travel behavior (Kroesen \& Handy, 2014; Vandenbulcke et al., 2009). Two main clustering approaches can be identified: i) clustering based on socio-demographic variables (Bergström \& Magnusson, 2003; Heinen et al., 2010); and ii) clustering based on mode-use variables (Anable, 2005; Gatersleben \& Appleton, 2007). This study considers socio-demographic variables, set of personal characteristics that define an individual, while mode-use variables show the cognitive state of readiness toward a transport mode. Both sets of variables (socio-economic and mode-use variables) were used for clustering since this approach identifies the cyclists precisely and offers a complete picture of their commuting patterns.

Previous research has found that cycling is related to a combination of socio-demographic variables, environmental aspects and cycling characteristics (Heinen et al., 2011; Zhao et al., 2018). In terms of socio-demographic variables, cycling use is influenced by age, gender, household composition, employment status, income and education (FernándezHeredia et al., 2014). Age generally influences sensorial abilities. Previous studies have concluded that cycling abilities decline with age (Van Cauwenberg et al., 2018). Gender appears to be more related to cycling culture than use (Garrard et al., 2008), but other researchers have reported that cycling is more popular among young male adults (Bull et al., 2000; Xing et al., 2010). Household composition influences cycling frequency; larger households are likely to cycle more frequently (Boumans \& Harms, 2005). Employment status and income affect vehicle ownership and purpose choice. Pucher and Renne (2003) found that non-car-owning low-income employees greatly increased their likelihood of walking and cycling, while high-income employees tended to cycle for sport or leisure. Education has more influence on perception than on cycling frequency, which may be due to the view of the environmental, social, and economic and personal benefits of using this mode of transport (Xing et al., 2018).

In regard to cycling-use variables, both environmental (e.g. zero $\mathrm{CO}_{2}$ emissions) and non-environmental aspects (e.g. traveling flexibility and opportunities for commercial activities) are seen as essential for adopting the bicycle for commuting (Bryceson et al., 2003; Handy \& Xing, 2011; Heinen et al., 2010; Lall et al., 2017). Cycling is perceived as environmentally friendly, which influences its share among pro-environmental riders (Clark et al., 2016). Woods and Masthoff (2017) associate cycling with flexibility, particularly in congested urban areas, while other authors state that cycling is even more convenient for suburban residents in SSA cities (Bryceson et al., 2003; Cervero, 2000, 2013), as it offers speedy access to jobs, health services and social activities, most of which are connected by unpaved roads in high-density unplanned settlements that are impenetrable by car. The perceived cycling opportunities for commercial activities were reported by Mutiso and Behrens (2011), who found that in most SSA cities, cycle-taxis are a feeder to public transport and serve as a source of income for many families.

The objective of this research is therefore to identify which socio-demographic and cycling-use variables can be used to identify the cluster of cycling commuters, using travel pattern mapping to reveal how far cycle commuting in SSA cities is similar to other locations where cycling has been studied in depth. Combining quantitative and qualitative approaches could provide additional insights for understanding cycling potential in developing cities in the African context.

\section{Research methodology}

\subsection{Case study description}

The empirical focus is the city of Quelimane, Mozambique, a representative example of a medium-size SSA city. It has a population of 195,758 inhabitants (INE, 2008), and is the fourth largest city in Mozambique. It is located $1620 \mathrm{~km}$ north of the capital city, Maputo. Quelimane is divided into three different functional zones (Figure 1). At the core is the central business district, CBD (Z1), which has $25.2 \%$ of the total population (density of $85.4 \mathrm{inh} / \mathrm{ha}$ ) and a job density of 4.8 jobs/ha. The second zone is called the city periphery (Z2), a mix of formal and informal settlements hosting 


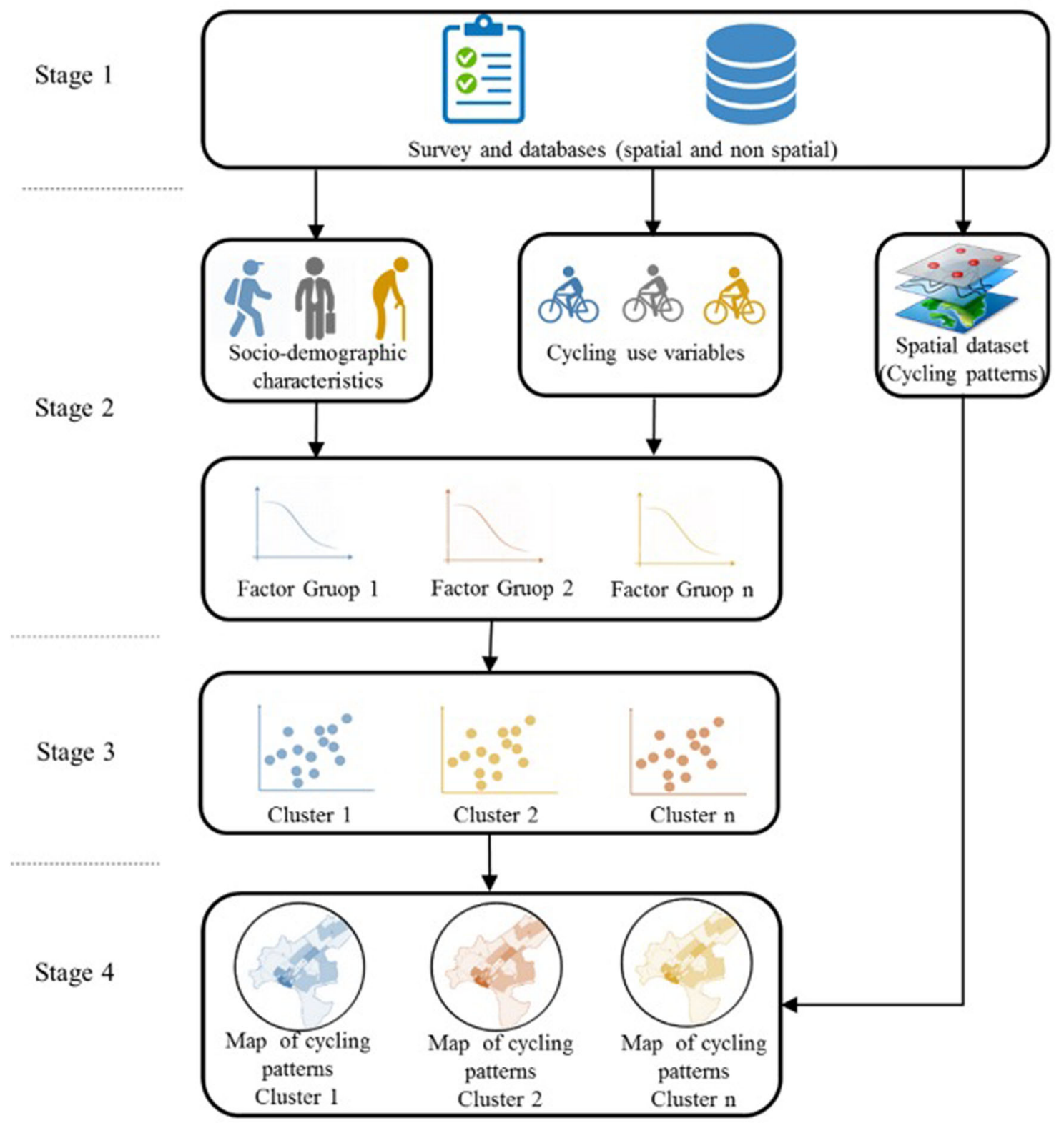

Figure 2. Diagram of the research methodology.

$44.8 \%$ of the city's population, with demographic and job densities of 28.2 and 0.9 respectively. The suburban areas (Z3) are mainly low-density informal settlements, including vast agricultural lands. They are home to $30 \%$ of the total population and have 9.5 inhabitants per hectare and a job density of 0.8. Quelimane is undergoing a process of urban sprawl, although a large number of services and transport infrastructures are still located in the inner city. There are small clusters of high-income residents in the inner city, while the majority of low-income residents live in the periphery. The urban sprawl dynamic reinforces car use and originates a higher number of long commuting trips, mostly by motorized modes.

There is very limited information on transport and mobility in Quelimane. In any case, cycling is a very popular mode of transport as it is cheap, easy to maintain and pleasant due to the flat topography (Nkurunziza et al., 2012). However, the perception of the municipal authorities is that cycling use is waning, while car use is on the rise. It is worth noting that there are no formal public transport services in the city. This lack of transport services originates that cycling became the only mode of transport for those without car availability. Bike services -including bike-taxisare a valid alternative due to the high unemployment rates and low-income levels among the population. In contrast, the mentioned lack of public transport also causes rather high rates of car ownership among medium and highincome families.

\subsubsection{Research design}

A four-stage approach was designed to identify and profile clusters of cycling commuters based on socio-demographic and cycling-use variables. A map of their travel patterns was obtained from cyclists' historical trip data, captured after 
recreating their previous day's trip and schematized as follows (Figure 2).

\section{1) Data gathering}

The study examines a broad array of the socio-demographic and cycling-use variables in the case study. Due to a lack of official mobility data from the municipality, an online and face-to-face survey was designed and administered to collect empirical data. The survey was conducted from July to December 2017 and the main target population was commuters, namely people who travel daily to reach various major activities (e.g. work, selling in the market, school and health care). An online survey was enabled by randomly distributing 1284 invitation cards at three university campuses and 15 large commercial areas, as it was considered more likely to find people with internet access in such places. A total of 550 surveys were finally obtained following this description. Since a large proportion of the population (around 33\%) do not have regular access to the internet (USAID, 2016), face-to-face surveys were also conducted in 22 predefined locations across the city (e.g. markets, workplaces, cycle-taxi points). Several criteria were taken into consideration to identify suitable locations: (i) places with a high concentration of people from a wide variety of socio-demographic backgrounds; (ii) places with a high trip generation rate; (iii) places where the cycle-taxi mode predominates. In all cases, respondents were randomly selected, and a total of 535 additional surveys were obtained. This sampling approach was highly appropriate for the case study, as only a limited number of people have regular access to the internet. Finally, a total of 1085 commuter respondents were obtained, indicating a level of confidence of over $95 \%$ and a margin of error of $5 \%$. However, 449 of them were eliminated due to missing data, resulting in a total of 636 valid questionnaires.

The survey comprises three parts:

- The first part was mainly related to cycling-use variables, exploring the respondents' cycling frequency for different purposes (e.g. work, school, shopping, selling in markets, and leisure). Responses were scaled from 1 to 3 where $1=$ Never, $2=$ Irregular (less than three times a week), $3=$ Regular (three times a week or more).

- The second section asked about the trips taken the previous day and their itinerary, indicating the origins and destinations (O-D) and the departure time from each destination. This helped to understand cycling intensity among the different urban zones and assess the role of road quality in the cycling patterns. A set of different neighborhoods were incorporated into the survey to increase the accuracy of the responses.

- The third section focused on standard socio-demographic variables. Respondents were asked to provide information about their age, gender, income, household composition, vehicle ownership, bicycle ownership, education level and employment.

The survey shows a modal split of $40 \%$ for walking, $35 \%$ for cycling, $8 \%$ for motorcycles, and $17 \%$ for cars. This confirms the high level of bike use, although it is declining as perceived by the city authorities.

2) Statistical analysis (sample characteristics and factor analysis): Statistical analysis was carried out on 22 key socio-demographic and cycling-use variables, providing the basic information on the case study. A chi-square non-parametric test was done to measure the variables' significance (Field, 2013), and frequency statistics were then used to explore the central tendency and dispersion of the collected data. This statistical analysis gave a clear picture of the whole sample population.

All significant socio-demographic and cycling-use variables were tested through factor analysis to determine their underlying factor structure using the principal component method. Promax rotation was used as a rotation method for handling very large datasets (Field, 2013). The robustness of the result was tested through the Kaiser-Meyer-Olkin (KMO) and Bartlett's test of sphericity to classify the relevant socio-economic and cycling-use variables that could help identify the cluster of commuter cyclists.

\section{3) Cluster analysis}

Finally, clusters of commuter cyclists were identified based on socio-demographic and cycling-use variables. This provided a basis to map cyclists' travel patterns and understand the influence of road quality on cycling mobility in the case study. Twostep cluster analysis was chosen as the clustering method due to its ability to handle very large categorical or continuous datasets and because this method automatically determines the optimum number of clusters (Field, 2013). The clustering criterion used was Akaike's information criterion (AIC), since it is sensitive to the variables in the study. Log-likelihood was specifically applied as a distance measure for its ability to mix different types of variables (Bacher et al., 2004).

\section{4) Mapping cyclists' travel patterns}

After identifying the clusters of cycling commuters, an origindestination matrix (O-D) was built by replicating the commuter cyclists' itineraries, which were spatially represented by means of Geographical Information System (GIS). The O-D pairs considered the Euclidean distances among different zones. The top O-D pairs ( $>5$ bicycle trips) were spatially represented by different colored lines - for example, red (trips occurring within Z1), purple (between Z1 and Z2) and light blue (Z2-Z2). This allows the identification of links with higher cycling intensity. The discussion focused on these O-D pairs to provide an important insight into the influence of road quality on cycling mobility. Cycling trips occurring within the same zone were considered to occur at the zone centroid, therefore not spatially represented. They were included in the statistics. The O-D pairs contain trip data such as cycling purpose, departure time and trip length.

\section{Results and discussion}

\subsection{Sample characteristics}

The survey set out to explore a large dataset of 12 significant socio-demographic and cycling-use variables influencing 
Table 1. Socio-demographic characteristics and cycling use of the sample.

\begin{tabular}{|c|c|c|}
\hline \multicolumn{2}{|l|}{ Variables } & Statistics $(n=636)$ \\
\hline \multicolumn{2}{|c|}{$\begin{array}{l}\text { Socio-demographic } \\
\text { Gender }\end{array}$} & $\%$ \\
\hline & Male & 71.1 \\
\hline & Female & 28.9 \\
\hline \multicolumn{3}{|c|}{ Age group } \\
\hline & Young (<35 years old) & 89.8 \\
\hline & Adults (35-55 years old) & 8.3 \\
\hline & Elderly ( $>55$ years old) & 1.9 \\
\hline \multicolumn{3}{|c|}{ Household composition } \\
\hline & Single parents with children & 67.8 \\
\hline & One-person household & 3.6 \\
\hline & Couple without children & 2.8 \\
\hline & Couple with children & 25.8 \\
\hline \multicolumn{3}{|c|}{ Employment status } \\
\hline & Unemployed & 6.4 \\
\hline & Student & 55.8 \\
\hline & Informal job & 24.7 \\
\hline & Formal job & 13.1 \\
\hline \multicolumn{3}{|c|}{ Education level } \\
\hline & Other levels & 3.9 \\
\hline & Primary & 21.5 \\
\hline & Secondary & 63.2 \\
\hline & University & 11.3 \\
\hline \multicolumn{3}{|c|}{ Income $(1000$ Mts $\approx 14 €)$} \\
\hline & $<3642$ Mts & 57.2 \\
\hline & $3642-25,000 \mathrm{Mts}$ & 41.2 \\
\hline & $>25,000 \mathrm{Mts}$ & 1.6 \\
\hline \multicolumn{3}{|c|}{ Vehicle ownership } \\
\hline & None & 30.7 \\
\hline & Only bicycle & 47.6 \\
\hline & Bicycle and motorized modes & 16.2 \\
\hline & Only motorized modes & 5.5 \\
\hline \multicolumn{3}{|c|}{ Bicycle availability } \\
\hline & No & 41.5 \\
\hline & Yes & 58.5 \\
\hline \multicolumn{3}{|c|}{ Cycling use (cycling frequency) } \\
\hline \multicolumn{3}{|c|}{ Work/study } \\
\hline & Never & 0.9 \\
\hline & Irregular (less than three times a week) & 36.2 \\
\hline & Regular (three times a week or more) & 44.3 \\
\hline \multicolumn{3}{|c|}{ 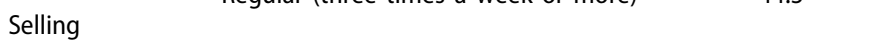 } \\
\hline & Never & 0.8 \\
\hline & Irregular (less than three times a week) & 16.0 \\
\hline & Regular (three times a week or more) & 8.2 \\
\hline \multicolumn{3}{|c|}{ Bicycle-taxi/carrying loads } \\
\hline & Never & 0.6 \\
\hline & Irregular (less than three times a week) & 7.7 \\
\hline & Regular (three times a week or more) & 7.7 \\
\hline \multicolumn{3}{|c|}{ Leisure/shopping } \\
\hline & Never & 1.6 \\
\hline & Irregular (less than three times a week) & 56.6 \\
\hline & Regular (three times a week or more) & 10.1 \\
\hline
\end{tabular}

cycling commuters in the case study (Table 1). In terms of socio-demographic variables, the sample distribution is fairly similar to the distribution of the Mozambican population in regard to age, income and paid work. Students and single-parent households are overrepresented in the sample and women are underrepresented. Although the sample correctly represents the Mozambican population with respect to some socio-demographic variables, it should be noted that it includes only daily commuters. A total of 636 correctly completed questionnaires were obtained, of which $71.1 \%$ were men. The unequal gender distribution is basically explained by three aspects: (i) most of the women in Quelimane are not integrated in economic activities, (ii) they have limited access to the internet, which forced us to conduct long face-to-face interviews and often resulted in incomplete questionnaires, and (iii) fewer women or possibly even none use bicycles for taxi activities.
In regard to age, there was a large proportion of young respondents (average age 23). The household category of single parents with children $(67.8 \%)$ was the most representative, followed by couples with children (25.8\%). These household categories are also the most representative in Mozambique (Javier \& Pedro, 2016). In regard to employment status, a large proportion of the respondents are students $(55.8 \%)$, followed by informal workers $(24.7 \%)$. The largest share among the different education categories is the secondary education level (63.2\%), followed by primary education $(21.5 \%)$ and university graduates $(11.3 \%)$. This has an important influence on monthly household income and available modes in the household. A large proportion of the respondents have incomes below the minimum wage (57.2\%) which is about $3642.00 \mathrm{Mts} /$ month $(\approx 51.87$ Euros/ month). $47.6 \%$ of the respondents own only a bicycle and $30.7 \%$ do not own any mode of transport. With respect to the number of bicycles owned, $58.5 \%$ of the respondents said they owned at least one or more bicycles.

In regard to cycling frequency to work/school, $44.3 \%$ of the respondents are regular cycling commuters (three times a week or more), $36.2 \%$ are irregular commuters (fewer than three times a week) and $0.9 \%$ are non-bicycle commuters (never cycle). Cycling frequency for selling in markets/streets is done mainly by irregular cycling commuters $(16.0 \%)$, followed by regular cycling commuters $(8.2 \%)$ and non-bicycle commuters $(0.8 \%)$. Cycling frequency for bicycle-taxi is equally dominated by regular and irregular cycling commuters $(7.7 \%)$. Cycling frequency for leisure/shopping corresponds mainly to irregular cycling commuters (56.6\%), followed by regular commuters (10.1\%). On average, the sample population made 3.36 bicycle trips per day, and the average cycling distance is $2.98 \mathrm{~km}(\mathrm{SD}=2.21 \mathrm{~km})$.

\subsection{Factor analysis}

Table 2 shows the factor loadings of the variables influencing bicycle commuting in Quelimane. Six factor groups were found, with the Kaiser-Meyer-Olkin (KMO) measure of sampling adequacy of 0.68 , the goodness of fit $=772.97$, $\mathrm{df}=120$ and $\mathrm{sig}=0.00$, which is statistically acceptable. However, only factor groups 1-4 (a total of 9 variables) were considered meaningful for cluster analysis based on an eigenvalue $>1$ and the scree plot.

Factor 1 (F1) includes age, household composition and employment status. These variables influence the social role of the individual and therefore their cycling frequency. Factor 2 (F2) refers to education level and income, variables that evidently impact individual social status and consequently cycling perception. Factor 3 (F3) consists of the type of vehicles available in the household and the number of bicycles and denotes an individual's mode availability dimension. Factor $4(\mathrm{~F} 4)$ is composed of the variables for cycling frequency to work/school and cycling frequency for leisure/shopping, which describes individual cycling habits. 


\begin{tabular}{|c|c|c|c|c|}
\hline \multirow[b]{2}{*}{ Variables } & \multicolumn{4}{|c|}{ Factors } \\
\hline & F1 (social role) & F2 (social status) & F3 (mode availability) & F4 (cycling habits) \\
\hline Age & 0.89 & & & \\
\hline Household composition & 0.90 & & & \\
\hline Employment status & 0.81 & & & \\
\hline Education level & & 0.87 & & \\
\hline Income & & 0.76 & & \\
\hline Vehicle ownership & & & 0.66 & \\
\hline Bicycle availability & & & 0.89 & \\
\hline Cycling frequency to work/school & & & & 0.63 \\
\hline Cycling frequency for leisure/shopping & & & & 0.90 \\
\hline Eigenvalue & 2.77 & 2.23 & 1.56 & 1.19 \\
\hline$\%$ of variance explained $(n=48.44)$ & 17.31 & 13.96 & 9.72 & 7.45 \\
\hline
\end{tabular}

\subsection{Clusters of cycling commuters}

Following the Twostep cluster analysis, three different clusters of cycling commuters were identified according to (i) household composition, (ii) cycling frequency to work/study and (iii) employment (Table 3). In Cluster \#1 (informal workers with children), the individuals surveyed were basically couples with children who regularly commuted to work/ study by bicycle (three times a week or more) and who had an informal job. This cluster accounts for $31.30 \%$ of the respondents. Cluster \#2 (short distance students) comprised students in single-parent households with children who regularly commute to work/study by bicycle (three times a week or more). This cluster accounts for $47.90 \%$ of the respondents. Cluster \#3 (occasional cyclists) contains students in single-parent households with children who irregularly commute to work/study by bicycle (less than three times a week). This cluster is composed of $20.80 \%$ of the respondents.

A brief profile of each cluster is discussed below; the analysis includes cycling patterns for the different zones in the city.

\subsubsection{Cluster 1: informal workers with children}

This cluster is composed mostly of couples with children who regularly use the bike to commute to informal jobs. It has a relatively large share of male respondents (78\%) and consequently a smaller share of women (22\%). The average age ( 32 years) is higher than the sample average ( 23 years). The dominant type of household in this cluster is couples with children (88.9\%), a category that represents only $25.8 \%$ of the sample respondents. Regarding employment status, there is a larger share of informal workers $(52.5 \%$ versus $24.7 \%$ in the sample). This cluster has the highest proportion of university graduates (16\%), and thus a higher average income and vehicle ownership. Consequently, a smaller proportion have secondary education certificates than the global sample (46.9\% versus $63.2 \%)$. Some $54.9 \%$ of the respondents belong to the medium-income wage group. Regarding vehicle ownership, $57.4 \%$ of the respondents own a bicycle and only $16.7 \%$ own no mode of transport. Most of the individuals in the cluster $(68.6 \%)$ have access to one or more bicycles.

To understand the travel patterns for Cluster 1, it is worth analyzing the intra- and inter-zone trip distribution
(Table 4). The intensity of O-D pairs of cycling trips is shown in Figure 3.

Only $6 \%$ of all cycling trips take place within the CBD, and the average travel distance is $1.46 \mathrm{~km}(\mathrm{SD}=0.73 \mathrm{~km})$. This lower share of cycling trips within $\mathrm{Z1}$ can be justified by the fact that it concentrates the majority of high-income individuals (Lall et al., 2017), who have higher car ownership. Pochet and Cusset (1999) found that cycling utility in SSA cities declines as income rises. Work/school (4\%) is the primary cycling purpose. The highest trip intensity is toward commercial/service areas. Roads within Z1 are paved, welllit and well-connected, which is critical for ensuring a safe and comfortable cycling environment. However, due to the fast-moving motorized traffic and the lack of bike lanes, cyclists are exposed to road accidents. Studies in SSA cities indicate that despite the low traffic volume, late afternoon and evening are dangerous times for cycling due to bad driver behavior, as drunk driving is the main cause of accidents (Verster \& Fourie, 2018).

Most of the cycling trips from Z2 are oriented toward Z1 (17\%). Selling/as a cycle-taxi (9\%), followed by work/school (5\%) are the primary cycling purposes. The most frequent O-D pairs are observed between poor residential areas (Z2) and commercial/service areas (Z1). On average they travel about $2.19 \mathrm{~km}(\mathrm{SD}=1.19 \mathrm{~km})$. This is the classic cycling pattern in most SSA cities. Most young unemployed men must live near the city center if they hope to cycle daily to the inner city to find decent jobs (Lall et al., 2017). Many informal workers cycle to earn their livelihood, and therefore have no specific destination and are less influenced by road quality. They often use a bicycle as a mobile carrying platform to sell in the streets and for uses as a cycle-taxi. Most of the trips take place at off-peak hours (7\%), when the lowtraffic volume makes cycling safer and encourages the use of bicycle-taxis, particularly among women. However, African women sit sidesaddle on bicycle-taxis, which poses a serious safety risk. Cyclists at peak-hours (5\%) are mostly street vendors, since the high rate of motorized traffic means more potential customers, particularly at the afternoon peak when people return home.

$49 \%$ of cycling trips take place within Z2: $33 \%$ for selling/as a bicycle-taxi, $11 \%$ for work/school and $5 \%$ for other purposes. The high share of trips for selling is justified by the fact that the city periphery concentrates most of the low-income individuals and a vast network of informal 
Table 3. Descriptive statistics of the cycling commuter clusters identified.

\begin{tabular}{|c|c|c|c|}
\hline Variables & $\begin{array}{c}\text { Cluster } 1 \\
\text { (informal workers with children) }\end{array}$ & $\begin{array}{c}\text { Cluster } 2 \\
\text { (short-distance students) }\end{array}$ & $\begin{array}{c}\text { Cluster } 3 \\
\text { (occasional cyclists) }\end{array}$ \\
\hline Socio-demographic & & Statistics (\%) & \\
\hline \multicolumn{4}{|l|}{ Age group } \\
\hline & 71.0 & 98.0 & 99.1 \\
\hline Adults (35-55 years old) & 25.3 & 2.0 & 0.9 \\
\hline Elderly ( $>55$ years old) & 3.7 & - & - \\
\hline \multicolumn{4}{|l|}{ Household composition } \\
\hline Single parents with children & - & 94.8 & 96.3 \\
\hline Single-person household & 3.7 & 4.0 & 3.7 \\
\hline Couple without children & 7.4 & 1.2 & - \\
\hline Couple with children & 88.9 & - & - \\
\hline \multicolumn{4}{|l|}{ Employment status } \\
\hline Unemployed & 4.3 & 6.0 & 5.6 \\
\hline Student & 9.9 & 70.2 & 86.1 \\
\hline Informal job & 52.5 & 16.5 & 6.5 \\
\hline Formal job & 33.3 & 7.3 & 1.9 \\
\hline \multicolumn{4}{|l|}{ Education level } \\
\hline Other & 7.4 & 2.8 & 3.7 \\
\hline Primary & 29.6 & 12.5 & 23.1 \\
\hline Secondary & 46.9 & 74.6 & 63.9 \\
\hline University & 16.0 & 10.1 & 9.3 \\
\hline \multicolumn{4}{|l|}{ Income $(1000$ Mts $\approx 14 €)$} \\
\hline$<3642$ Mts & 42.0 & 55.2 & 65.7 \\
\hline $3642-25,000$ Mts & 54.9 & 44.4 & 34.3 \\
\hline$>25,000 \mathrm{Mts}$ & 3.1 & 0.4 & - \\
\hline \multicolumn{4}{|l|}{ Vehicle ownership } \\
\hline None & 16.7 & 24.6 & 40.7 \\
\hline Only bicycle & 57.4 & 56.5 & 31.5 \\
\hline Both bicycle and motorized modes & 19.8 & 14.5 & 18.5 \\
\hline Only motorized modes & 6.2 & 4.4 & 9.3 \\
\hline \multicolumn{4}{|l|}{ Bicycle availability } \\
\hline No & 31.4 & 34.6 & 50.0 \\
\hline Yes & 68.6 & 65.4 & 50.0 \\
\hline \multicolumn{4}{|l|}{ Cycling-use variables (cycling frequency) } \\
\hline Never & - & - & 5.6 \\
\hline Irregular (less than three times a week) & 30.9 & 32.7 & 94.4 \\
\hline Regular (three times a week or more) & 69.1 & 67.3 & - \\
\hline \multicolumn{4}{|l|}{ Leisure/shopping } \\
\hline Never & 0.8 & 0.5 & 9.7 \\
\hline Irregular (less than three times a week) & 83.2 & 79.2 & 85.5 \\
\hline Regular (three times a week or more) & 16.0 & 20.2 & 4.8 \\
\hline - & $31.30 \%$ & $47.90 \%$ & $20.80 \%$ \\
\hline
\end{tabular}

Table 4. \% of cycling trips by informal workers with children ( $n=642$ trips).

\begin{tabular}{|c|c|c|c|c|c|}
\hline \multirow[b]{2}{*}{ O-D pairs } & \multicolumn{3}{|c|}{ Cycling purpose* } & \multicolumn{2}{|c|}{ Departure period* } \\
\hline & Formal jobs & Informal jobs & Other & Peak hours & Off-peak hours \\
\hline & Work/school & Selling/as a bicycle-taxi & & & \\
\hline $\mathrm{Z1-Z1}$ & $4 \%$ & $1 \%$ & $1 \%$ & $2 \%$ & $6 \%$ \\
\hline $\mathrm{Z1-Z2}$ & $5 \%$ & $9 \%$ & $3 \%$ & $5 \%$ & $7 \%$ \\
\hline Z1-Z3 & $0 \%$ & $1 \%$ & $1 \%$ & $0 \%$ & $1 \%$ \\
\hline $\mathrm{Z} 2-\mathrm{Z2}$ & $11 \%$ & $33 \%$ & $5 \%$ & $17 \%$ & $43 \%$ \\
\hline Z2-Z3 & $6 \%$ & $7 \%$ & $3 \%$ & $5 \%$ & $7 \%$ \\
\hline Z3-Z3 & $2 \%$ & $6 \%$ & $2 \%$ & $0 \%$ & $6 \%$ \\
\hline
\end{tabular}

*Differences in the percentage of trips between "cycling purpose" and "departure period" are due to missing data in the sample.

markets (Lall et al., 2017; UN-Habitat, 2011). On average they travel $2.30 \mathrm{~km}(\mathrm{SD}=1.28 \mathrm{~km})$. The most frequent $\mathrm{O}-\mathrm{D}$ pairs correspond to neighborhoods with larger informal markets and bus terminals. At peak hours, the concentration of trucks, buses, motorcycles, handcarts and pedestrians makes cycling impracticable in many road sections. For street sellers, finding a favorable place for selling is very challenging, so they must start out early in the morning. This may explain why $43 \%$ of the cycling trips within Z2 occur in the off-peak period. Most commuters in Z2 are captive cyclists, which means that the bicycle is the only available alternative since many roads in $\mathrm{Z} 2$ are not accessible by car due to the dense unplanned informal settlements, with narrow and disconnected roads.

The average travel distance between $\mathrm{Z} 2-\mathrm{Z3}$ is about $6.05 \mathrm{~km}(\mathrm{SD}=2.25 \mathrm{~km})$, which is far higher than the cluster average of $3.11 \mathrm{~km}(\mathrm{SD}=2.17 \mathrm{~km})$; a possible explanation is that selling/as a bicycle-taxi (11\%) is the main cycling purpose. Mutiso and Behrens (2011) underline that bicycle-taxi fares are dependent on trip length, so bicycle-taxi drivers prefer long trips to maximize their revenues. Z3 is basically an agricultural area, and the roads connecting this zone are often wide, unpaved and lacking basic cycling facilities such as street lights. It has low traffic volume which makes 
cycling safer, although it is uncomfortable due to the unpaved road surface, particularly for bicycle-taxi operators who regularly carry passengers and/or heavy loads. Bicycletaxi drivers are often physically fit young men (Mutiso \& Behrens, 2011), which ensures a faster connection and also protection for late afternoon and evening commuters, highlighting the fact that bicycle-taxis not only provide door-todoor transport but also play an important security role for more vulnerable individuals.

\section{Cluster 2: short-distance students}

This cluster is composed mostly of students in single-parent households with children who regularly cycle to their workplace or school. This cluster has a large share of male respondents $(70 \%)$. The average age is 20 years (similar to the global sample, which is 23 years). This is a very common household type in most SSA cities, probably due to low average life expectancy and polygamy (UNFPA, 2016). Most have only a secondary education (74.6\%), which influences their average income. Most households' (55.2\%) income is below the minimum wage. Vehicle ownership and the number of bicycles available in the household are similar to Cluster 1. Table 5 breaks down all Cluster 2 trips according to cycling purpose and travel behavior (departure time).

Most trips between $\mathrm{Z} 1$ and Z2 are commuting to work/ school (4\%), other purposes (2\%) and selling/as a bicycletaxi (1\%). The average travel distance is $1.80 \mathrm{~km}$ $(\mathrm{SD}=1.01 \mathrm{~km})$. The lower school cycling share can be explained by the fact that a large proportion of parents do not encourage their children to cycle to school. Most secondary schools are located along the main roads where there is no cycling infrastructure, street signage or cycle crossings, which makes cycling to school unsafe. $7 \%$ of cycle trips are off-peak. This is likely because the majority of public schools in Mozambique open between 6:30 AM and 7 AM, somewhat before morning peak hours.

Cycling within Z2 covers short distances: the average cycling distance within $\mathrm{Z} 2$ is $1.15 \mathrm{~km}(\mathrm{SD}=0.55 \mathrm{~km})$, typically cycling to school (Emond \& Handy, 2012). 39\% of this cluster cycle to work/school, $12 \%$ for selling/as a bicycle-taxi and $9 \%$ for other purposes. The roads in the city periphery are often narrow and unpaved, making cycling safer due to a relative absence of motorized traffic. $45 \%$ of trips occur off-peak. These narrow roads afford shade, which is highly appreciated in summer, and probably explains the high cycling share within this zone. Cycling within Z2 allows parents to reduce their daily travel expenditure to school, thus increasing school attendance, which has a significant impact on reducing poverty. However, there are no proper parking facilities at school, which discourages cycling due to the fear of bicycle thieves.

Some $11 \%$ of cycling trips take place between Z2 and Z3. $6 \%$ are for work/school, $4 \%$ for selling/as a bicycle-taxi and $1 \%$ for other purposes. The average cycling distance is $5.02 \mathrm{~km}(\mathrm{SD}=3.83 \mathrm{~km})$, which is substantially more than the sample average of $2.69 \mathrm{~km}(\mathrm{SD}=2.25 \mathrm{~km})$. A possible explanation is that suburban areas are remote and deprived of basic services such as education and health (UN-Habitat,

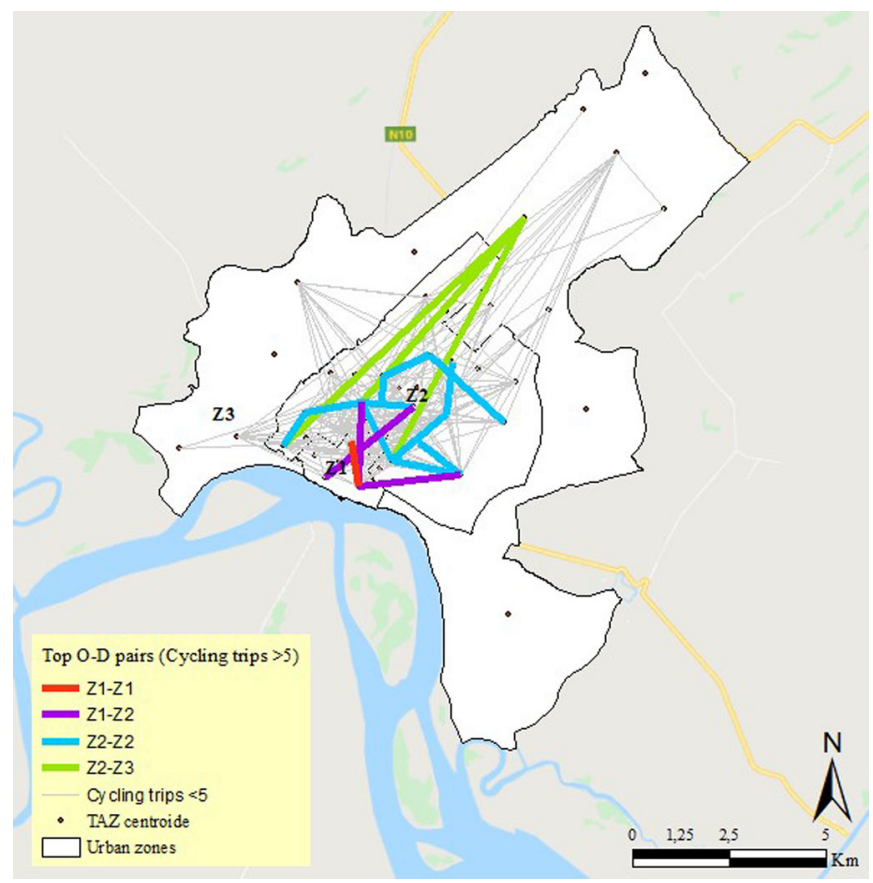

Figure 3. Most frequent $O-D$ pairs of cycling trips by informal workers with children.

2011), so students must travel long distances in search of alternatives. Long daily distances affect the cycling decisions of poor households, who are forced to restrict their trips to the most essential purposes such as work, selling or farming. This discourages school attendance, which contributes to increasing poverty.

\section{Cluster 3: occasional cyclists}

This cluster is composed mostly of students who occasionally cycle to school or work. The average age is 19 years. Household composition, employment status, education level and income are similar to Cluster 2 . The majority are single parents with children (96.3\%), students (86.1\%) and secondary level students (63.9\%), with incomes below the minimum wage $(65.7 \%)$. This cluster has the largest share of female respondents (41\%), which probably justifies the greater proportion of low-income households since many single-parent households in Mozambique are female-headed and most are poor. A glance at the structure of the urban Mozambican population shows that females represent 53.5\% of the total population (INE, 2015).

Table 6 shows that trips within the CBD (Z1-Z1) correspond to $5 \%$ of all trips. $3 \%$ are for selling/as a bicycle-taxi and $2 \%$ for other purposes. The average travel distance is $0.36 \mathrm{~km} \quad(\mathrm{SD}=0.06 \mathrm{~km})$, below the cluster average of $2.84 \mathrm{~km}(\mathrm{SD}=2.38 \mathrm{~km})$. The lower share of cycling trips between $\mathrm{Z} 1-\mathrm{Z} 1$ can be explained by the fact that the inner core in most SSA cities is a high-income residential area, so few individuals cycle for their daily activities (Lall et al., 2017). This cycling pattern can be seen in Figure 5, where a higher cycling intensity is observed between O-D pairs connecting to large informal markets. Roads connecting market places in $\mathrm{Z1}$ are often paved and are congested at peak hours when the main intersections are occupied by street 
Table 5 . $\%$ of cycling trips by short-distance students ( $n=766$ trips).

\begin{tabular}{|c|c|c|c|c|c|}
\hline \multirow[b]{2}{*}{ O-D pairs } & \multicolumn{3}{|c|}{ Cycling purpose* } & \multicolumn{2}{|c|}{ Departure period* } \\
\hline & Formal jobs & Informal jobs & Other & Peak hours & Off-peak hours \\
\hline & Work/school & Selling/as a bicycle-taxi & & & \\
\hline $\mathrm{Z1-Z1}$ & $7 \%$ & $2 \%$ & $2 \%$ & $3 \%$ & $5 \%$ \\
\hline Z1-Z2 & $4 \%$ & $1 \%$ & $2 \%$ & $4 \%$ & $7 \%$ \\
\hline Z1-Z3 & $2 \%$ & $1 \%$ & $0 \%$ & $1 \%$ & $1 \%$ \\
\hline $\mathrm{Z2}-\mathrm{Z2}$ & $39 \%$ & $12 \%$ & $9 \%$ & $20 \%$ & $45 \%$ \\
\hline Z2-Z3 & $6 \%$ & $4 \%$ & $1 \%$ & $3 \%$ & $5 \%$ \\
\hline Z3-Z3 & $4 \%$ & $3 \%$ & $1 \%$ & $1 \%$ & $5 \%$ \\
\hline
\end{tabular}

*Differences in the percentage of trips between "cycling purpose" and "departure period" are due to missing data in the sample.

Table $6 . \%$ of cycling trips by occasional cyclists ( $n=325$ trips).

\begin{tabular}{|c|c|c|c|c|c|}
\hline \multirow[b]{2}{*}{ O-D pairs } & \multicolumn{3}{|c|}{ Cycling purpose* } & \multicolumn{2}{|c|}{ Departure period* } \\
\hline & Formal jobs & Informal jobs & Other & Peak hours & Off-peak hours \\
\hline & work/school & selling/as a bicycle-taxi & & & \\
\hline Z1-Z1 & $0 \%$ & $3 \%$ & $2 \%$ & $4 \%$ & $5 \%$ \\
\hline $\mathrm{Z1-Z2}$ & $2 \%$ & $4 \%$ & $1 \%$ & $5 \%$ & $4 \%$ \\
\hline Z1-Z3 & $0 \%$ & $0.4 \%$ & $0.4 \%$ & $0 \%$ & $1 \%$ \\
\hline $\mathrm{Z} 2-\mathrm{Z2}$ & $8 \%$ & $36 \%$ & $25 \%$ & $34 \%$ & $37 \%$ \\
\hline Z2-Z3 & $3 \%$ & $5 \%$ & $4 \%$ & $1 \%$ & $4 \%$ \\
\hline Z3-Z3 & $0 \%$ & $3 \%$ & $3 \%$ & $6 \%$ & $0 \%$ \\
\hline
\end{tabular}

*Differences in the percentage of trips between "cycling purpose" and "departure period" are due to missing data in the sample.

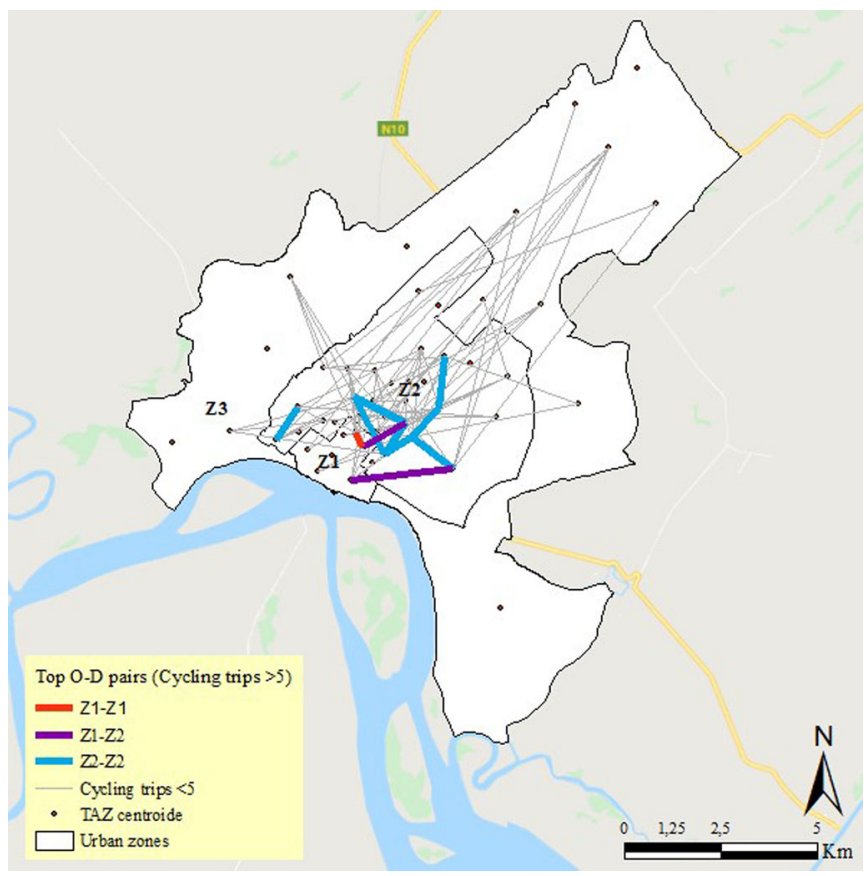

Figure 5. Most frequent O-D pairs of cycling trips by occasional cyclists.

vendors, which narrows the streets. This contributes to road disputes between different transport modes and makes cycling unsafe. According to Garrard et al. (2008), women often avoid cycling in such conditions and tend to cycle off-peak.

Cycling trips between $\mathrm{Z} 1$ and $\mathrm{Z} 2$ represent $7 \%$ of all trips: $4 \%$ for selling, $2 \%$ for work/school and $1 \%$ for other purposes. The average travel distance is $1.97 \mathrm{~km}(\mathrm{SD}=1.25 \mathrm{~km})$. Oakil et al. (2016) report that cycling intensity is higher if the primary purpose is utilitarian and the commuting distance shorter. Some researchers (Lall et al. (2017) have stated that road quality in SSA cities declines rapidly beyond the inner city, making cycling unsafe due to the lack of bike lanes. Women are often the most penalized because many cannot endure the hardships of such trips, and so become passive cyclists (bicycle-taxi passengers), while others avoid cycling altogether. This prevents their participation in economic activities and ties them to poverty.

The highest number of bicycle trips (69\%) take place inside the city periphery (Z2-Z2). Cycling for other purposes $(25 \%)$ has particularly high relevance. The average travel distance is $1.60 \mathrm{~km}(\mathrm{SD}=1.07 \mathrm{~km})$. Such relatively long cycling distances for non-utilitarian trips may reveal typical occasional cycling characteristics (Heesch et al., 2015). The primary cycling purpose is selling (36\%) and most trips are off-peak. According to Bryceson et al. (2003) and Lall et al. (2017), the city periphery (Z2) often concentrates the majority of informal job opportunities, and therefore attracts this type of cycling trips. This cluster also has a larger share of female respondents. Some authors report that most women in SSA cities are dedicated to domestic activities and to activities in the informal economy, such as selling in local markets or working on family farms (Kes \& Swaminathan, 2006; Wodon \& Blackden, 2006). The quality of the roads in $\mathrm{Z} 2$ is poor and they lacking most facilities; they tend to be narrow, uneven, unpaved and disconnected, with no street lights or drainage. This kind of road network deters car trips and encourages cycling by day, particularly during the hours of sunlight since buildings offer protection from the sun. However, cycling through these streets is unsafe by night or in the long tropical rainy season, inducing a shift to the main roads, which cyclists must share with fast-moving automobiles and dense traffic, thus exposing them to the risk of accidents.

\section{Conclusions}

This study identifies and profiles clusters of cycling commuters in the city of Quelimane based on socio-demographic and cycling-use variables. The O-D matrix shows their cycling patterns. Cycling commuters were clustered 
Table 7. Overall percentage of cycling trips per travel purpose and distance $(n=1733)$.

\begin{tabular}{|c|c|c|c|c|c|c|c|c|}
\hline \multirow[b]{3}{*}{ Clusters } & \multicolumn{4}{|c|}{ Cycling purpose (\%) } & \multicolumn{4}{|c|}{ Distance $(\mathrm{km})$} \\
\hline & \multirow{2}{*}{$\begin{array}{l}\text { work/ } \\
\text { school }\end{array}$} & \multirow{2}{*}{$\begin{array}{c}\text { selling/ } \\
\text { bicycle-taxi }\end{array}$} & \multirow[b]{2}{*}{ Other } & \multirow[b]{2}{*}{ Total } & \multicolumn{4}{|c|}{$\%$} \\
\hline & & & & & $<2$ & $2-5$ & $>5$ & Total \\
\hline C1-Informal workers with children & 13 & 21 & 7 & 41 & 15 & 19 & 7 & 44 \\
\hline C2-Short-distance students & 29 & 12 & 9 & 50 & 20 & 14 & 5 & 39 \\
\hline C3-Occasional cyclists & 1 & 5 & 3 & 9 & 10 & 7 & 3 & 20 \\
\hline Total & 43 & 38 & 19 & 100 & 45 & 40 & 15 & 100 \\
\hline
\end{tabular}

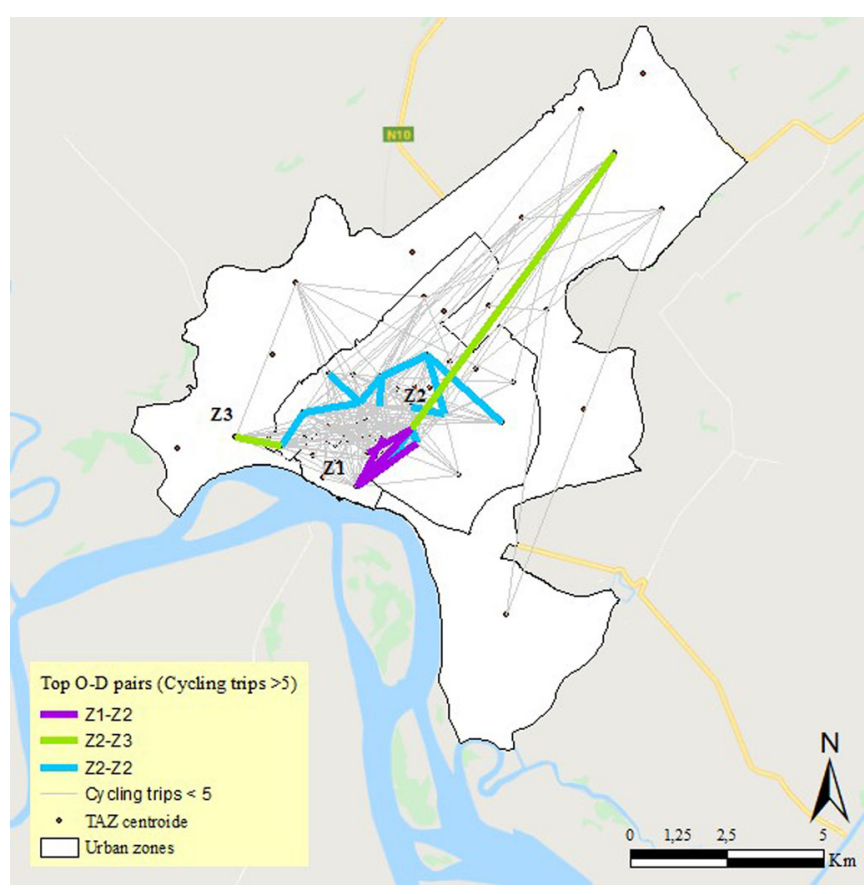

Figure 4. Most frequent O-D pairs of cycling trips by short-distance students.

into three groups according to three socio-demographic and attitudinal variables: household composition, employment status and cycling frequency to work/school. The clusters identified are informal workers with children, short-distance students and occasional cyclists. Their cycling patterns were spatially visualized using GIS. Selling and bicycle-taxi are the main cycling purpose, highlighting that the bicycle is used as a work tool.

Table 7 presents a summary of cycling trips per travel purpose and distance. The majority of trips are regular to work (either formal or informal) and to study. Also, students use their bicycle for informal activities as selling things and transporting persons. Trip distances are up to $5 \mathrm{~km}$ long, which can explain why most trips are within Z2, where half of the population lives and cover their daily activities. Individual from cluster 1 ( $41 \%$ of total) cycle to sell/bicycletaxi $(21 \%)$ as major activity. About $19 \%$ cycle medium distances $(2-5 \mathrm{~km})$. In Cluster 2, 29\% cycle to school, covering less than $2 \mathrm{~km}$. Occasional cyclists often cycle to sell/bicycletaxi, and half cycle short distances, less than $2 \mathrm{~km}$.

When comparing these findings with Figures 3-5, a high cycling intensity can be observed within $\mathrm{Z} 2$, which hosts most people and many informal activities. However, the bike patterns contrast with other types of cities where trips to work and shop have the $\mathrm{CBD}$ as the main destination
(Cervero, 2000, 2013). The reasons for this could be the following: (i) The urban layout influences cyclists' behavior. Cycling in SSA cities is mostly for poor, while wealthier people own cars and make trips to $\mathrm{CBD}$ where roads are paved and most formal jobs and retail activities are located. (ii) Lack of public transport. For the poor majority, the bicycle is the only available mode of transport and it is also used as an informal taxi. (iii) Poor road conditions beyond the city-periphery (Z2) that makes it inaccessible by car and thus safer for cycling.

On the other hand, the results shown in Tables $1-3$ indicate that attitudes toward cycling are basically influenced by individual social roles, so individuals in larger households and low-income employees cycle more frequently. This is consistent with other studies in the field (Boumans \& Harms, 2005; Pucher \& Renne, 2003; Zhao et al., 2018). The O-D pairs enabled us to assess the cycling patterns for the different clusters. In Cluster 1 and 3, the main cycling purpose is to transport goods to sell in local markets. On average, the respondents' cycle short-medium distances. This is consistent with Bryceson et al. (2003), who consider these cycling patterns to be linked to informal jobs in the city periphery associated with selling goods in nearby markets. In Cluster 2, the primary purpose is cycling to school. This was expected since the dense informal settlements and narrow streets offer a safe cycling environment (UN-Habitat, 2011), which encourages parents to allow their children to cycle to school. Nevertheless, the described patterns should be complemented by more advance modeling approaches to identify the causal relationships among cycling patterns and the built environment.

Overall, this study highlights two main contributions. First, cycling intensity is rather low between the CBD and the city-periphery, because the rather differences among those areas are in terms of road quality, access to cars and location of activities for people with different income levels. In Quelimane, most cycle trips take place in the city periphery (Z2), while most of the car trips are located in CBD (Z1). The second contribution is that the use of bike as taxi is affected by variables related to business models, rather than by variables of distances to destinations. For this reason, bicycle-taxi operators are more likely to cycle longer distances than the rest of the population to increase their revenues. That can alert about the risk to exclusively consider the linear relationship between travel distance and cycling choice in the context of SSA cities.

Based on those important aspects, transportation strategies should therefore be targeted to each type of traveler (here defined as clusters of cyclists). Due to the differences 
observed, very few lessons from studies in other socio-economic contexts can be applied to SSA. There is a clear need for mobility data for planning in SSA cities to serve as a basis for decision-making organized in a systemic way. This paper has generated the databases for the city of Quelimane, which allows the design of efficient policies aimed at producing a positive impact on mobility patterns.

The results show that despite the similarities in attitudes to cycling among the clusters, commuters behave according to the characteristics of the urban fabric in which they live, work, shop, and enjoy their leisure. Mapping cyclists' travel patterns for specific zones is crucial to define the geographical areas where customized policies can be implemented. For instance, most Cluster 1 commuters cycle regularly as a way to perform informal jobs, and Cluster 2 commuters to go to school. Most of these two clusters are located in the city-periphery. Cycling policies should be designed to reduce travel time, particularly when connecting residential zones with large market areas. Efficient safety measures are also required - particularly on the main crossings to schools -, and safe bicycle parking in schools to reduce bicycle theft and make cycling to school more attractive.

From a societal point of view, cycling offers immense commuting benefits in SSA cities; however, little is known about cyclist profiles. In order to develop precise policies that encourage cycling, further studies should consider attitudinal variables in identifying homogenous groups of commuter cyclists. This should precisely reveal different needs for different groups of commuter cyclists, with the goal of implementing the best possible solutions tailored to each profile.

\section{Acknowledgments}

The authors would like to acknowledge the support of the TRANSyTUPM, the staff of the Quelimane city council and the Universidade Pedagogica Delegação de Quelimane. The authors would finally like to thank Dr. Alphonse Nkurunziza from the University of Rwanda for his comments and the three anonymous reviewers of this paper for their valuable feedback.

\section{Funding}

This research is funded by the Ministry of Science and Technology, Higher and Technical Vocational Education of the Republic of Mozambique.

\section{ORCID}

Classio Joao Mendiate (D) http://orcid.org/0000-0002-8917-0211 Julio Alberto Soria-lara (iD http://orcid.org/0000-0002-2383-6332 Andres Monzon (iD) http://orcid.org/0000-0001-7265-2663

\section{References}

Abane, A. M. (2011). Travel behaviour in Ghana: empirical observations from four metropolitan areas. Journal of Transport Geography, 19(2), 313-322. https://doi.org/10.1016/j.jtrangeo.2010.03.002
Acheampong, R. A., \& Siiba, A. (2018). Examining the determinants of utility bicycling using a socio-ecological framework: An exploratory study of the Tamale Metropolis in Northern Ghana. Journal of Transport Geography, 69, 1-10. https://doi.org/10.1016/j.jtrangeo. 2018.04.004

Alando, W. (2017). A framework for inclusive transport planning in medium-sized Sub-Saharan African cities. (PhD), Techinische Universitat Dortmund. Retrieved from https://core.ac.uk/download/ pdf/83041839.pdf

Anable, J. (2005). Complacent car addicts' or 'aspiring environmentalists'? Identifying travel behaviour segments using attitude theory. Transport Policy, 12(1), 65-78. https://doi.org/10.1016/j.tranpol.2004.11.004

Assailly, J. P. (2017). Road safety education: What works?. Patient Education and Counseling, 100, S24-S29. https://doi.org/10.1016/j. pec.2015.10.017

Bacher, J., Wenzig, K., \& Vogler, M. (2004). SPSS TwoStep cluster-a first evaluation. Journal of Statistical Software, 23. p.

Bergström, A., \& Magnusson, R. (2003). Potential of transferring car trips to bicycle during winter. Transportation Research Part A: Policy and Practice , 37(8), 649-666. https://doi.org/10.1016/S09658564(03)00012-0

Boumans, A., Harms, L. J. R. (2005). Part-time employment and travel patterns of women in the Netherlands (2).

Bryceson, D. F., Mbara, T. C., \& Maunder, D. (2003). Livelihoods, daily mobility and poverty in Sub-Saharan. Transport Reviews, 23(2), 177-196. https://doi.org/10.1080/01441640309891

Bull, F., Milligan, R., Rosenberg, M., \& MacGowan, H. (2000). Physical activity levels of Western Australian adults 1999. Perth, WA, Health Department of Western Australia and Sport and Recreation Way2Go, Western Australian Government.

Cervero, R. (2000). Informal transport in the developing world. UNHABITAT.

Cervero, R. (2013). Linking urban transport and land use in developing countries. Journal of Transport and Land Use, 6(1), 7-24. https://doi. org/10.5198/jtlu.v6i1.425

Clark, B., Chatterjee, K., \& Melia, S. (2016). Changes to commute mode: The role of life events, spatial context and environmental attitude. Transportation Research Part A: Policy and Practice, 89, 89-105. https://doi.org/10.1016/j.tra.2016.05.005

Diaz Olvera, L., Plat, D., \& Pochet, P. (2008). Household transport expenditure in Sub-Saharan African cities: measurement and analysis. Journal of Transport Geography, 16(1), 1-13. https://doi.org/10. 1016/j.jtrangeo.2007.04.001

Dimitriou, H. T. (2006). Towards a generic sustainable urban transport strategy for middle-sized cities in Asia: Lessons from Ningbo, Kanpur and Solo. Habitat International, 30(4), 1082-1099. https:// doi.org/10.1016/j.habitatint.2006.02.001

Emond, C. R., \& Handy, S. L. (2012). Factors associated with bicycling to high school: insights from Davis, CA. Journal of Transport Geography, 20(1), 71-79. https://doi.org/10.1016/j.jtrangeo.2011.07.008

Fernández-Heredia, Á., Monzón, A., \& Jara-Díaz, S. (2014). Understanding cyclists' perceptions, keys for a successful bicycle promotion. Transportation Research Part A: Policy and Practice, 63, 1-11. https://doi.org/10.1016/j.tra.2014.02.013

Field, A. (2013). Discovering statistics using IBM SPSS statistics. In M. Carmichael (ed.), 4th ed. Sage.

Garrard, J., Rose, G., \& Lo, S. K. (2008). Promoting transportation cycling for women: the role of bicycle infrastructure. Preventive Medicine, 46(1), 55-59. https://doi.org/10.1016/j.ypmed.2007.07.010

Gatersleben, B., \& Appleton, K. M. (2007). Contemplating cycling to work: Attitudes and perceptions in different stages of change. Transportation Research Part A: Policy and Practice, 41(4), 302-312. https://doi.org/10.1016/j.tra.2006.09.002

Handy, S. L., \& Xing, Y. (2011). Factors correlated with bicycle commuting: A study in six small US cities. International Journal of Sustainable Transportation, 5(2), 91-110. https://doi.org/10.1080/ 15568310903514789

Heesch, K. C., Giles-Corti, B., \& Turrell, G. (2014). Cycling for transport and recreation: associations with socio-economic position, 
environmental perceptions, and psychological disposition. Preventive Medicine, 63, 29-35. https://doi.org/10.1016/j.ypmed.2014.03.003

Heesch, K. C., Giles-Corti, B., \& Turrell, G. (2015). Cycling for transport and recreation: associations with the socio-economic, natural and built environment. Health \& Place, 36, 152-161. https://doi.org/ 10.1016/j.healthplace.2015.10.004

Heinen, E., Maat, K., \& van Wee, B. (2011). The role of attitudes toward characteristics of bicycle commuting on the choice to cycle to work over various distances. Transportation Research Part D: Transport and Environment, 16(2), 102-109. https://doi.org/10.1016/ j.trd.2010.08.010

Heinen, E., van Wee, B., \& Maat, K. (2010). Commuting by bicycle: An overview of the literature. Transport Reviews, 30(1), 59-96. https://doi.org/10.1080/01441640903187001

INE. (2008). Estatísticas do Distrito de Cidade de Quelimane. Av. Ahmed Sekou Touré, ${ }^{\circ}$ 21; Caixa Postal 493, Maputo. www.ine. gov.mz

INE. (2015). Estatísticas e Indicadores Sociais, 2013 -2014. MaputoMozambique: Instituto Nacional de Estatística. http://www.ine.gov.mz/ estatisticas/estatisticas-demograficas-e-indicadores-sociais/estatisticase-indicadores-sociais/estatisticas-e-indicadores-sociais-2014/view

Javier, E., Pedro, O. (2016). Accelerating poverty reduction in Mozambique: challenges and opportunities. http://documents.worldbank.org/curated/en/383501481706241435/Accelerating-poverty-reductionin-Mozambique-challenges-and-opportunities

Kes, A., \& Swaminathan, H. J. G. (2006). Gender and time poverty in sub-Saharan.

Kroesen, M., \& Handy, S. (2014). The relation between bicycle commuting and non-work cycling: Results from a mobility panel. Transportation, 41(3), 507-527. https://doi.org/10.1007/s11116-0139491-4

Lall, S. V., Henderson, J. V., \& Venables, A. J. (2017). Africa's cities: Opening doors to the world: The World Bank.

Massink, R., Zuidgeest, M., Rijnsburger, J., Sarmiento, O. L., \& Van Maarseveen, M. (2011). The climate value of cycling. Natural Resources Forum, 35(2), 100-111. https://doi.org/10.1111/j.14778947.2011.01345.x

Mutiso, W., \& Behrens, R. J. S. (2011). 'Boda Boda'bicycle taxis and their role in urban transport systems: Case studies of Kisumu and Nakura, Kenya.

Nkurunziza, A., Zuidgeest, M., Brussel, M., \& Van Maarseveen, M. (2012). Examining the potential for modal change: Motivators and barriers for bicycle commuting in Dar-es-Salaam. Transport Policy, 24, 249-259. https://doi.org/10.1016/j.tranpol.2012.09.002

Oakil, A. T. M., Ettema, D., Arentze, T., \& Timmermans, H. (2016). Bicycle commuting in the Netherlands: An analysis of modal shift and its dependence on life cycle and mobility events. International Journal of Sustainable Transportation, 10(4), 376-384. https://doi. org/10.1080/15568318.2014.905665

Pendakur, V. S. (2005). Non-motorized transport in African cities: Lessons from experience in Kenya and Tanzania. Sub-Saharan Africa Transport Policy Program Working Paper, 80.

Pochet, P., \& Cusset, J.-M. (1999). Cultural barriers to bicycle use in Western African cities. IATSS Research, 23(2), 43-50.

Pucher, J., Buehler, R., Bassett, D. R., \& Dannenberg, A. L. (2010). Walking and cycling to health: A comparative analysis of city, state, and international data. American Journal of Public Health, 100(10), 1986-1992. https://doi.org/10.2105/ajph.2009.189324
Pucher, J., \& Renne, J. L. (2003). Socioeconomics of urban travel: evidence from the 2001 NHTS. Transportation Quarterly, 57(3), 49-77.

UN-Habitat. (2011). Sustainable mobility in African cities. United Nations Human Settlements Programme.

UNFPA. (2016). The demographic profile of African countries (97899944-68-06-5). Addis Ababa, Ethiopia: https://www.uneca.org/sites/ default/files/PublicationFiles/demographic_profile_rev_april_25.pdf

USAID. (2016). Mozambique Mobile Access and Usage Study, Household Survey Results.

Van Cauwenberg, J., Clarys, P., De Bourdeaudhuij, I., Ghekiere, A., de Geus, B., Owen, N., \& Deforche, B. (2018). Environmental influences on older adults' transportation cycling experiences: A study using bike-along interviews. Landscape and Urban Planning, 169, 37-46. https://doi.org/10.1016/j.landurbplan.2017.08.003

Vandenbulcke, G., Thomas, I., de Geus, B., Degraeuwe, B., Torfs, R., Meeusen, R., \& Int Panis, L. (2009). Mapping bicycle use and the risk of accidents for commuters who cycle to work in Belgium. Transport Policy, 16(2), 77-87. https://doi.org/10.1016/j.tranpol.2009. 03.004

Verster, T., \& Fourie, E. (2018). The good, the bad and the ugly of South African fatal road accidents. South African Journal of Science, 114(7/8), 63-69. https://doi.org/10.17159/sajs.2018/20170427

Wallrapp, C., \& Faust, H. (2008). Bicycle ambulances in rural Uganda: analysis of factors influencing its usage. World Transport Policy and Practice, 14(2), 38-46.

Winters, M., Brauer, M., Setton, E. M., \& Teschke, K. (2010). Built environment influences on healthy transportation choices: bicycling versus driving. Journal of Urban Health : bulletin of the New York Academy of Medicine, 87(6), 969-993. https://doi.org/10.1007/ s11524-010-9509-6

Wodon, Q., \& Blackden, C. M. (2006). Gender, time use, and poverty in sub-Saharan Africa: The World Bank.

Woods, R., \& Masthoff, J. (2017). A comparison of car driving, public transport and cycling experiences in three European cities. Transportation Research Part A: Policy and Practice, 103, 211-222. https://doi.org/10.1016/j.tra.2017.06.002

Xing, Y., Handy, S. L., \& Mokhtarian, P. L. (2010). Factors associated with proportions and miles of bicycling for transportation and recreation in six small US cities. Transportation Research Part D: Transport and Environment, 15(2), 73-81. https://doi.org/10.1016/j. $\operatorname{trd} .2009 .09 .004$

Xing, Y., Volker, J., \& Handy, S. (2018). Why do people like bicycling? Modeling affect toward bicycling. Transportation Research Part F: Traffic Psychology and Behaviour, 56, 22-32. https://doi.org/10.1016/ j.trf.2018.03.018

Yang, M., \& Zacharias, J. (2016). Potential for revival of the bicycle in Beijing. International Journal of Sustainable Transportation, 10(6), 517-527. https://doi.org/10.1080/15568318.2015.1012281

Yao, M., \& Wang, D. (2018). Mobility and travel behavior in urban China: The role of institutional factors. Transport Policy, 69, 122-131. https://doi.org/10.1016/j.tranpol.2018.05.012

Zhao, C., Nielsen, T. A. S., Olafsson, A. S., Carstensen, T. A., \& Meng, X. (2018). Urban form, demographic and socio-economic correlates of walking, cycling, and e-biking: Evidence from eight neighborhoods in Beijing. Transport Policy, 64, 102-112. https://doi.org/10. 1016/j.tranpol.2018.01.018 